Tạp chí Khoa học Đại học Quốc gia Hà Nội: Khoa học Y Dược

Website: https://js.vnu.edu.vn/MPS

\title{
Một số yếu tố nguy cơ bệnh tim mạch trên cán bộ một trường Đại học ở Hà Nội năm 2016
}

\author{
Vũ Vân Nga, Đỗ Thị Quỳnh, Vũ Thị Mai Anh, Vũ Thị Thơm* \\ Khoa Y duợc, Đại học Quốc gia Hà Nội, 144 Xuân Thủy, Cầu Giấy, Hà Nội, Việt Nam \\ Nhận ngày 27 tháng 9 năm 2018 \\ Chỉnh sửa ngày 08 tháng 11 năm 2018; Chấp nhận đăng ngày 25 tháng 12 năm 2018
}

\begin{abstract}
Tóm tắt: Những năm gần đây, tỷ lệ mắc và tử vong do bệnh tim mạch ở Việt Nam ngày càng gia tăng. Chính vì vậy, chúng tôi tiến hành nghiên cứu mô tả cắt ngang một số yếu tố nguy cơ bệnh tim mạch trên 269 cán bộ, nhân viên một trường đại học ở Hà Nội năm 2016 trong độ tuổi từ 20 đến 64 . Kết quả cho thấy $43,8 \%$ đối tượng thừa cân - béo phì; $12,3 \%$ tăng huyết áp; $29,0 \%$ rối loạn lipid máu. Tỷ lệ mắc các yếu tố nguy cơ ở nam cao hơn nữ. Tỷ lệ cán bộ nhân viên của trường mắc tăng huyết áp và rối loạn lipid máu thấp hơn so với cộng đồng. Có sự liên quan giữa giới tính với tình trạng thừa cân béo phì, tăng huyết áp, rối loạn lipid máu, trong khi nhóm tuổi chủ yếu liên quan tới tình trạng tăng huyết áp $(\mathrm{p}<0,001)$.
\end{abstract}

Từ khóa: Yếu tố nguy cơ bệnh tim mạch, thừa cân béo phì, tăng huyết áp, rối loạn lipid máu.

\section{1. Đặt vấn đề}

Trong những năm gần đây, các bệnh lý tim mạch được xác nhận là nguyên nhân hàng đầu gây tử vong trên toàn cầu. Theo thống kê của Tổ chức Y tế thế giới, bệnh tim mạch (BTM) chiếm tới $10 \%$ gánh nặng bệnh tật và làm chết khoảng 16 - 17 triệu người mối năm $[1,2]$. Bệnh không chỉ gây nguy hiểm tính mạng mà còn kéo theo các hậu quả về kinh tế - xã hội do các biến chứng tử vong và tàn tật thường xảy ra trong độ tuổi có năng suất lao động cao nhất và có vai trò xã hội chủ lực [1]. Tuy nhiên, đa số

\footnotetext{
*Tác giả liên hệ. ĐT.: 84-1677968818.

Email: thomtbk5@gmail.com

https://doi.org/10.25073/2588-1132/vnumps.4126
}

các bệnh tim mạch có thể dự phòng được thông qua việc cải thiện các yếu tố nguy cơ (YTNC) [1]. Tăng huyết áp (THA), rối loạn lipid máu (RLLM), đái tháo đường (ĐTĐ), thừa cân béo phì (TCBP)... được coi là các yếu tố nguy cơ chính, có thể thay đổi của bệnh tim mạch.

Bên cạnh đó còn có các yếu tố nguy cơ không thể thay đổi như tuổi, giới tính, chủng tộc, tiền sử gia đình [3]. Trên thế giới, các nghiên cứu cho thấy tỷ lệ mắc các yếu tố nguy cơ có xu hướng gia tăng ở các nước có thu nhập thấp và trung bình. Ở Việt Nam, các nghiên cứu gần đây cho thấy khoảng $48 \%$ người dân mắc tăng huyết áp, $60-70 \%$ có tình trạng rối loạn lipid máu, 5,7\% mắc đái tháo đường... [4-6]. Nghiên cứu này được thực hiện nhằm mục tiêu đánh giá một số yếu tố nguy cơ của bệnh tim 
mạch trên cán bộ nhân viên một trường đại học ở Hà Nội năm 2016.

\section{2. Đối tượng và phương pháp nghiên cứu}

\section{1. Đối tượng nghiên cứu}

Hồ sơ khám sức khỏe định kỳ (SKĐK) của cán bộ nhân viên một trường đại học ở Hà Nội năm 2016. Các hồ sơ khám SKĐK có đầy đủ các thông tin cá nhân (tuổi, giới), các thông tin lâm sàng và cận lâm sàng như chiều cao, cân nặng, huyết áp, lipid máu (Cholesterol toàn phần, Triglycerid, HDL-c, LDL-c).

Tiêu chuẩn loại trù̀: Các hồ sơ khám sức khỏe không đủ thông tin cần thiết.

Thời gian và địa điểm nghiên cứu: Nghiên cứu được thực hiện từ tháng 10/2017 đến tháng 12/2017, số liệu được thu thập từ hồ sơ khám sức khỏe định kỳ của cán bộ nhân viên một trường đại học ở Hà Nội tại phòng khám 182 Lương Thế Vinh - Bệnh viện Đại học Quốc gia Hà Nội.

\subsection{Phuơng pháp nghiên cưu}

Nghiên cứu mô tả cắt ngang, sử dụng công thức tính cỡ mẫu xác định cho một tỷ lệ với $\mathrm{Z}=$ 1,96 (độ tin cậy 95\%); $\alpha=0,05$ (mức ý nghĩa thống kê), $\varepsilon=0,125$ (khoảng sai lệch mong muốn); $\mathrm{p}=0,495$ [7].

Cỡ mẫu ước tính được là 250, sau khi tiến hành thu thập và làm sạch số liệu chúng tôi thu được 269 hồ sơ khám sức khỏe hợp lệ.

Các chỉ số lâm sàng: Chiều cao, cân nặng được đo đúng quy chuẩn, chỉ số khối cơ thể (BMI) được tính theo công thức: $\mathrm{BMI}=$ cân nặng/(chiều cao $)^{2}\left(\mathrm{~kg} / \mathrm{m}^{2}\right)$. Huyết áp tâm thu (HATT) và Huyết áp tâm trương (HATTr) được đo 1 lần (với bao huyết áp ALPK II) ở tư thế ngồi. Nếu kết quả bất thường, đối tượng sẽ được kiểm tra huyết áp lần 2 sau khi nghỉ ngơi tại chỗ $5-10$ phút.

Mẫu máu xét nghiệm: $2 \mathrm{ml}$ máu toàn phần được lấy từ tĩnh mạch, chống đông EDTA và bảo quản ở $4-8{ }^{\circ} \mathrm{C}$ đến khi làm xét nghiệm sinh hóa (Cholesterol toàn phần, Triglycerid, HDLc, LDL-c).

Một số tiêu chuẩn đự̣c sử dụng trong nghiên cứu: Thừa cân - béo phì theo tiêu chuẩn WPRO $2000, \mathrm{BMI} \geq 23 \mathrm{~kg} / \mathrm{m}^{2}$ [8]. Tăng huyết áp theo tiêu chuẩn JNC VII [9]. Rối loạn Lipid máu theo NCEP 2002 khi có một trong bốn rối loạn: Cholesterol toàn phần $\geq 6,2$ $\mathrm{mmol} / \mathrm{l}$; HDL-c $\leq 1,03 \mathrm{mmol} / \mathrm{l}$; Triglycerid $\geq$ 2,26 mmol/1 hoặc LDL-c $\geq 4,13 \mathrm{mmol} / 1$ [10]

Các số liệu khám sức khỏe được nhập vào phần mềm quản lý khám chữa bệnh tại phòng khám 182 Lương Thế Vinh, làm sạch và xử lý kết quả trên Excel 2010, SPSS 22.0. Kiểm định $\mathrm{t}$ - test và kiểm định khi bình phương được sử dụng để phân tích kết quả.

Đạo đức nghiên cứu: Thông tin cá nhân của cán bộ tham gia khám SKĐK được bảo mật trong nghiên cứu này nhằm đảm bảo vấn đề $\mathrm{y}$ đức. Số liệu đã được Bệnh viện Đại học Quốc gia Hà Nội cho phép công bố dưới dạng bài báo.

\section{Kết quả và bàn luận}

\section{1. Đặc điểm của đối tuợng nghiên cúu}

Các kết quả về đặc điểm của đối tượng nghiên cứu được trình bày ở bảng 1 . Trong số 269 đối tượng, có 142 nam và 127 nữ với độ tuổi từ 20 đển 64 , tuổi trung bình là 38,17 . Nhóm tuổi dưới 40 chiếm đa số ở cả hai giới (55,6\% ở nam, 63,8\% ở nữ), trong khi nhóm tuổi 60 trở lên chỉ có ở nam, điều này là do tuổi nghỉ hưu của hai giới khác nhau. Nhìn chung, ngoại trừ $\mathrm{HDL}-\mathrm{c}$, giá trị trung bình của các chỉ số về BMI, huyết áp, lipid máu của nam đều cao hơn nữ $(\mathrm{p}<0,05)$. BMI trung bình của quần thể nghiên cứu là $22,95 \pm 2,55 \mathrm{~kg} / \mathrm{m}^{2}$, ở ngưỡng giới hạn trên của giá trị bình thường $(18,5$ $\left.22,9 \mathrm{~kg} / \mathrm{m}^{2}\right)$ được WPRO đề xuất cho người

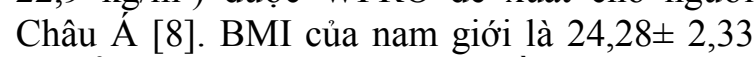
$\mathrm{kg} / \mathrm{m}^{2}$ - tương đương với mức tiền béo phì, cho thấy tình trạng thừa cân béo phì ở nam giới khá phổ biến trên nhóm cán bộ nhân viên này. Giá trị $\mathrm{BMI}$ trung bình và $\mathrm{BMI}$ của nam giới mà 
chúng tôi thu được cũng có sự chênh lệch so với một số nghiên cứu trên cộng đồng như Vietnam STEPS Report năm 2015 (BMI ${ }_{\text {chung: }}$ : 22,$\left.0 ; \mathrm{BMI}_{\text {nam }}: 22,0 ; \mathrm{BMI}_{\text {nữ }}: 22,0\right)$ [11] hay Tan Van Bui năm $2009\left(\mathrm{BMI}_{\mathrm{nam}}: 21,1 ; \mathrm{BMI}_{\mathrm{nữ}}: 21,2\right)$ [12], tuy nhiên giá trị BMI ở nữ không khác biệt đáng kể. Huyết áp tâm thu (HATT) và tâm trương (HATTr) trong nhóm cán bộ nhân viên ĐHQGHN thấp hơn kết quả trong nghiên cứu cộng đồng của Quang Ngoc Nguyen năm 2009 ở người trên 30 tuổi (nam: 135/80,4 mmHg; nữ: $129,1 / 77,3 \mathrm{mmHg}$ ) [13], kết quả này tương đồng với kết quả STEPS Vietnam Report 2015 ở người trưởng thành 18-69 tuổi (huyết áp chung: $119,9 / 77,1 \mathrm{mmHg}$; nam: $124,4 / 79,4$ mmHg; nữ: 119,9/77,1 mmHg) [11]. Các giá trị về lipid máu của nhóm nghiên cứu trong mức giới hạn bình thường.

\section{Bảng 1. Đặc điểm của đối tượng nghiên cứu}

\begin{tabular}{lllll}
\hline & $\begin{array}{l}\text { Nam } \\
\mathrm{n}=142 \\
(\overline{\boldsymbol{X}} \pm \mathrm{SD})\end{array}$ & $\begin{array}{l}\text { Nũ̃ } \\
\mathrm{n}=127 \\
(\overline{\boldsymbol{X}} \pm \mathrm{SD})\end{array}$ & $\begin{array}{l}\text { Trung bình chung } \\
\mathrm{N}=269 \\
(\overline{\boldsymbol{X}} \pm \mathrm{SD})\end{array}$ & Giá trị p \\
\hline Tuổi & $39,06 \pm 10,93$ & $37,18 \pm 7,85$ & $38,17 \pm 9,62$ & 0,103 \\
BMI $\left(\mathrm{kg} / \mathrm{m}^{2}\right)$ & $24,29 \pm 2,33$ & $21,45 \pm 1,84$ & $22,95 \pm 2,55$ & $<0,001$ \\
HATT & $122,36 \pm 14,86$ & $108,66 \pm 11,00$ & $115,89 \pm 14,84$ & $<0,001$ \\
HATTr & $79,30 \pm 9,8$ & $69,29 \pm 7,89$ & $74,57 \pm 10,23$ & $<0,001$ \\
Lipid máu & & & & \\
- Cholesterol toàn & $4,84 \pm 0,76$ & $4,44 \pm 0,68$ & $4,65 \pm 0,75$ & $<0,001$ \\
phần & $1,40 \pm 0,54$ & $1,69 \pm 0,61$ & $1,54 \pm 0,59$ & $<0,001$ \\
- HDL-C & $2,01 \pm 1,15$ & $1,06 \pm 0,50$ & $1,56 \pm 1,02$ & $<0,001$ \\
- Triglycerid & $2,49 \pm 0,63$ & $2,23 \pm 0,68$ & $2,37 \pm 0,67$ & 0,002 \\
- LDL-C & & & & \\
\hline
\end{tabular}

3.2 Tỷ lệ mắc một số yếu tố nguy co bệnh tim mach ở nhóm nghiên cúu

* Thừa cân béo phì

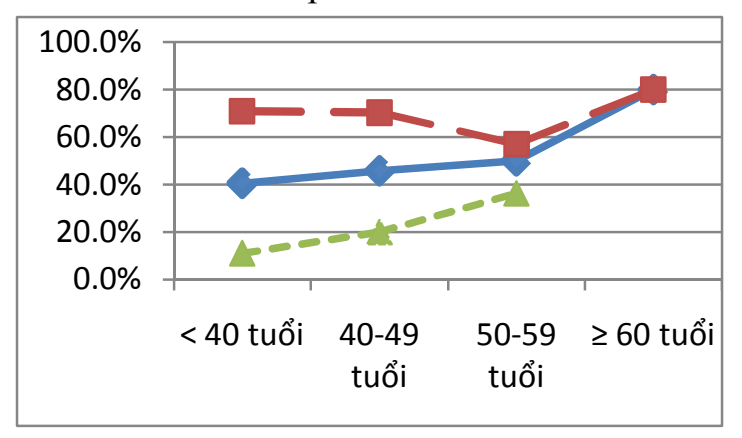

Hình 1. Tình trạng TC-BP theo nhóm tuổi.

Hệ thống phân độ thừa cân béo phì được WHO đề xuất cho người châu Á (WPRO) cho thấy tình trạng mắc thừa cân béo phì chiếm tỷ lệ khá cao ở cán bộ nhân viên (43,8\%). Trên cộng đồng, tỷ lệ mắc TC-BP khoảng 25-35\% và gần như tương đương giữa nam và nữ $[7,14,15]$.

Trên đối tượng nghiên cứu, như ở hình 1 chúng tôi nhận thấy không những tỷ lệ mắc cao hơn đáng kể so với cộng đồng, mà giới tính cũng có mối liên quan với tình trạng TC-BP (p $<0,001)$, do tỷ lệ mắc rất cao ở nam giới. Theo Viện Huyết học, Phổi, Tim quốc gia Hoa Kỳ, nguy cơ mắc TC-BP tăng ở nam giới, người ít hoạt động thể lực, uống rượu bia, chế độ ăn nhiều chất béo bão hòa và đồ ngọt [16]. Do vậy, đây có thể là yếu tố góp phần làm TC-BP trở nên phổ biến ở CBNV, đặc biệt là nam giới. Từ sự chênh lệch về tỷ lệ mắc này có thể thấy nữ nhân viên văn phòng có chế độ ăn uống, sinh hoạt hợp lý hơn nam nhân viên nói chung và nữ giới cùng độ tuổi nhưng làm ngành nghề khác nói riêng. Một số tác giả cũng đề cập tới sự ảnh hưởng của trình độ văn hóa và thu nhập đến tình trạng TC-BP $[14,17]$, tuy nhiên chúng tôi 
cho rằng cần có những nghiên cứu sâu hơn để làm rõ mối liên quan này.

Trong quần thể nghiên cứu, tình trạng thừa cân béo phì khá cao ở nam giới các nhóm tuổi (tỷ lệ mắc luôn trên $60 \%$ ) và tăng dần ở nữ giới, đặc biệt là nữ giới trong nhóm tuổi 50-59 (sau mãn kinh). Xu hướng cũng gặp trong các nghiên cứu trên cộng đồng Việt Nam của Oanh TH Trinh năm 2005 [14], Kiet A Ly năm 2010 [17] và trên cộng đồng các nước khu vực châu Á như nghiên cứu của N. Jitnarin tại Thái Lan năm 2011 [18] hay Hee Taik Kang tại Hàn Quốc năm 2014 [19]. Thừa cân - béo phì tác động không tốt tới huyết áp, lipid máu và tình trạng kháng insulin [20]. Do đó, tỷ lệ mắc TCBP tăng cao ở nam nhân viên văn phòng các nhóm tuổi cảnh báo đối tượng này rất dễ mắc các bệnh tim mạch. Đáng chú ý đây là nhóm đối tượng có năng suất và hiệu quả lao động cao, nếu không kiểm soát tốt các yếu tố nguy cơ của bệnh tim mạch sẽ để lại những thiệt hại đối với sự phát triển kinh tế xã hội. Công tác khám sức khỏe định kỳ, tư vấn chế độ ăn uống, luyện tập cũng như điều trị ban đầu bởi vậy đóng một vai trò quan trọng trong việc dự phòng, kiểm soát nguy cơ bệnh tim mạch.

* Tăng huyết áp

Bảng 2. Tình trạng huyết áp

\begin{tabular}{lllll}
\hline $\begin{array}{l}\text { Tuổi } \\
\text { (năm) }\end{array}$ & $\begin{array}{l}\text { Bình } \\
\text { thường } \\
\mathrm{n}(\%)\end{array}$ & $\begin{array}{l}\text { Tiền } \\
\text { THA } \\
\mathrm{n}(\%)\end{array}$ & $\begin{array}{l}\text { THA } \\
\text { độ } 1 \\
\mathrm{n}(\%)\end{array}$ & $\begin{array}{l}\text { THA } \\
\text { độ } 2 \\
\mathrm{n}(\%)\end{array}$ \\
\hline$<40$ & 86 & 66 & 7 & 1 \\
& $(65,6)$ & $(62,9)$ & $(33,3)$ & $(8,3)$ \\
$40-49$ & 33 & 23 & 9 & 7 \\
& $(25,2)$ & $(21,9)$ & $(42,9)$ & $(58,3)$ \\
$50-59$ & 12 & 13 & 4 & 3 \\
& $(9,2)$ & $(12,4)$ & $(19,0)$ & $(25)$ \\
$\geq 60$ & 0 & 3 & 1 & 1 \\
& $(0)$ & $(2,9)$ & $(4,8)$ & $(8,3)$ \\
Tổng & 131 & 105 & 21 & 12 \\
\hline
\end{tabular}

Trong 269 đối tượng nghiên cứu, có 39\% mắc tiền tăng huyết áp; $12,3 \%$ tăng huyết áp. Đáng chú ý, nghiên cứu cho thấy tỷ lệ mắc tăng huyết áp ở nam giới cao hơn nữ giới $(21,8 \%$ so với 1,6\%), sự khác biệt có ý nghĩa thống kê (p
$<0,001$ ) (bảng 2). Kết quả này tương tự với xu hướng trong các nghiên cứu trên cộng đồng của Duc Anh Ha và cs. năm 2011 (nam: 30\%, nữ: 19\%) [21] hay Pham Thai Son năm 2012 (nam: 28,3\%; nữ 23,1\%) [22]. Từ sau 40 tuổi, tỷ lệ mắc THA tăng gấp 4-5 lần. Đáng chú ý là gần $50 \%$ người mắc THA thuộc nhóm tuổi 40-49. Ở nhóm tuổi trên 60 , dù số lượng mẫu còn hạn chế nhưng có thể thấy không có đối tượng nào huyết áp bình thường, cảnh báo nguy cơ mắc tăng huyết áp tăng dần theo tuổi. Tuy nhiên, tỷ lệ mắc ở nhóm đối tượng nghiên cứu vẫn thấp hơn đáng kể so với tỷ lệ gặp trong nghiên cứu cộng đồng của Trịnh Xuân Thắng $(31,2 \%)$ [7] hay Vietnam STEPS Report (17,1\%) [11]. Trên cùng đối tượng cán bộ nhân viên, kết quả thu được khá tương đồng với nghiên cứu của $\mathrm{H}$ Van Minh và cs. năm 2006 (nam 21,2\%, nữ $7 \%$ ) [23]. Có sự liên quan giữa nhóm tuổi với tình trạng huyết áp ở nam giới và quần thể nói chung ( $\left.\mathrm{p}_{\text {nam giới }}<0,001 ; \mathrm{p}_{\text {chung }}<0,001\right)$. THA không kiểm soát chặt chẽ sẽ gây ra những biến chứng nặng nề như nhồi máu cơ tim và đột quy. Ước tính khoảng $54 \%$ số ca đột quỵ và $47 \%$ biến cố tim mạch toàn cầu là do THA [24]. Một số nghiên cứu gần đây đã chỉ ra rằng nguy cơ nhồi máu cơ tim và đột quỵ ở người 40-89 tuổi tăng gấp 2 lần khi HATT tăng mỗi $20 \mathrm{mmHg}$ hoặc HATTr tăng mỗi 10 mmHg [25]. Như vậy, việc tầm soát tăng huyết áp trong cộng đồng, đặc biệt là trên các đối tượng nguy cơ cao, điều chỉnh chế độ ăn uống sinh hoạt hợp lý và tuân thủ điều trị góp phần đáng kể làm giảm tỷ lệ mắc và dự phòng biến chứng của bệnh.

\section{* Rối loạn lipid máu}

Trong quần thể nghiên cứu, có $29 \%$ đối tượng mắc rối loạn lipid máu, thường gặp nhất là giảm nồng độ $\mathrm{HDL}-c$ và tăng nồng độ Triglycerid. Kết quả này khá tương đồng với nghiên cứu của Bùi Thị Nhung trên đối tượng người không béo phì năm 2016 tại Hà Nam [26] và nghiên cứu của Wichai Aekplakorn và cs. năm 2009 tại Thái Lan [27]. Tuy nhiên một số nghiên cứu trước đó trên cộng đồng Việt Nam cho kết quả tăng Cholesterol và Triglycerid là các rối loạn chiếm đa số $[6,7,28]$. 
Nghiên cứu cũng cho thấy tỷ lệ mắc rối loạn mỡ máu ở nam cao hơn nữ ở tất cả các thể rối loạn (hình 2). Kết quả này có thể do chế độ ăn uống, sinh hoạt ở nữ giới hợp lý hơn. Bên cạnh đó, nữ giới trong nghiên cứu của chúng tôi phần lớn là đối tượng chưa mãn kinh, estrogen còn tác động lên chuyển hóa chất béo, có thể giúp điều hòa nồng độ các lipid trong máu tốt hơn $[6,28]$. Tuy nhiên, theo khảo sát của STEPS Vietnam Report năm 2015, tỷ lệ mắc RLLM cao ở nhóm tuổi từ 40-49 cũng có thể do nhiều nguyên nhân khác như nhóm này thường ít hoạt động thể lực, sử dụng rượu bia nhiều hơn các nhóm tuổi khác [11].

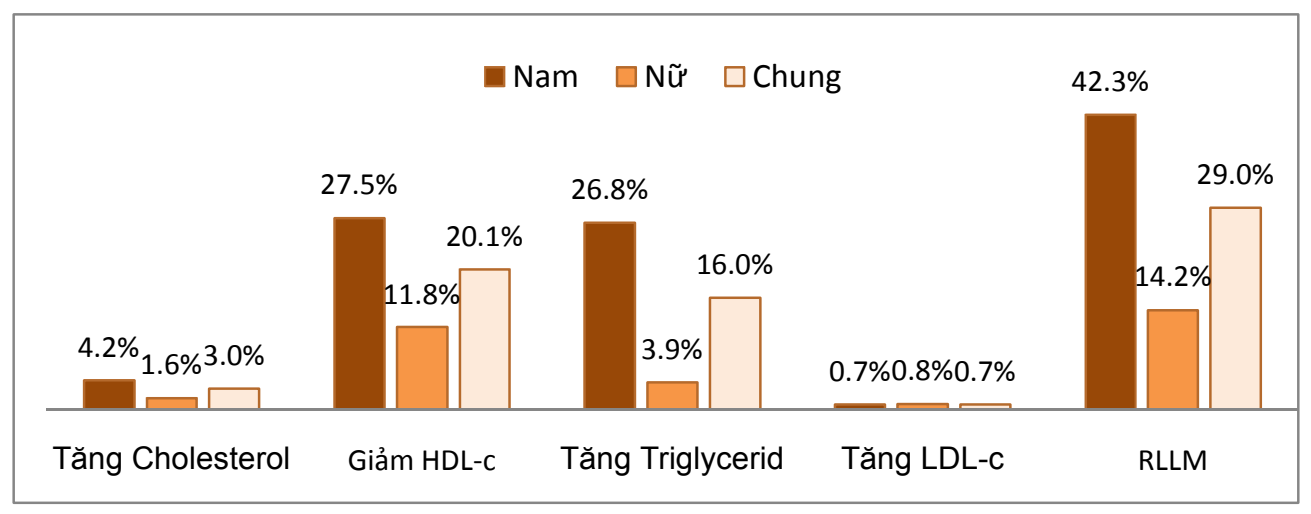

Hình 2. Các thể rối loạn Lipid máu trên nhóm nghiên cứu.

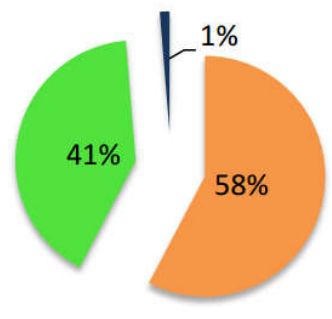

Hình 3. Rối loạn các chỉ số Lipid máu trên nhóm nghiên cứu.

Trên nhóm đối tượng nghiên cứu có mắc rối loạn lipid máu, đa số các trường hợp có rối loạn bất thường từ một đến hai chỉ số lipid với tổng tỷ lệ là $99 \%$ (hình 3). Nghiên cứu của Bùi Thị Nhung và cs. trên người không béo bụng, $\mathrm{BMI}$ bình thường năm 2016 cũng cho kết quả tương tự về xu hướng khi xét riêng các đối tượng mắc RLLM (bất thường 1 chỉ số lipid: $54,83 \%, 2$ chỉ số: $27,02 \%, 3$ chỉ số: $15,27 \%$, 4 chỉ số: $2,74 \%$ ) [26]. Tuy nhiên, có thể do hạn chế về cỡ mẫu và cách chọn đối tượng nghiên cứu nên kết quả chúng tôi thu được có rất ít đối tượng rối loạn 3 chỉ số, và không có đối tượng nào rối loạn cả 4 chỉ số lipid được khảo sát.

Bảng 3. Mối tương quan giữa một số yếu tố nguy cơ bệnh tim mạch

\begin{tabular}{llllllll}
\hline & Tuổi chung & BMI & HA TT & HA TTr & Cho & Tri & HDL-c \\
\hline BMI & 0,081 & & & & & & \\
HATT & $0,298^{\dagger}$ & $0,309^{\dagger}$ & & & & & \\
HATTr & $0,256^{\dagger}$ & $0,352^{\dagger}$ & $0,890^{\dagger}$ & & & & \\
Cho & $0,165^{*}$ & $0,187^{*}$ & $0,116^{*}$ & $0,178^{*}$ & & & \\
Tri & $0,152^{*}$ & $0,345^{\dagger}$ & $0,264^{\dagger}$ & $0,275^{\dagger}$ & $0,348^{\dagger}$ & & \\
HDL-c & $-0,026$ & $-0,221^{\dagger}$ & $-0,007$ & $-0,008$ & $0,203^{\dagger}$ & $-0,372^{\dagger}$ & \\
LDL-c & 0,119 & $0,144^{*}$ & 0,035 & 0,05 & $0,621^{\dagger}$ & $0,135^{*}$ & $-0,350^{\dagger}$ \\
\hline
\end{tabular}




\subsection{Mối tuơng quan giũa một số yếu tố nguy co bệnh tim mạch}

* Tương quan giữa chỉ số BMI với các yếu tố bệnh tim mạch

Trên 269 đối tượng nghiên cứu, chúng tôi nhận thấy BMI chủ yếu liên quan tới giá trị huyết áp tâm thu, huyết áp tâm trương, với hệ số tương quan $r$ lần lượt là 0,309 và 0,352 . Kết quả này khá tương đồng với khảo sát của Lê Thanh Chiến và cs. tại Việt Nam năm 2011, cho thấy BMI tương quan thuận với HATT và HATTr,với $r=0,41$ và 0,38 [29].

Phân tích ảnh hưởng của $\mathrm{BMI}$ với các chỉ số lipid máu, chúng tôi nhận thấy mức độ tương quan không cao giữa tăng BMI với tăng triglycerid $(\mathrm{r}=0,345)$, giảm HDL-c $(\mathrm{r}=$ $0,221)$, tăng cholesterol $(\mathrm{r}=0,187)$. Kết quả nghiên cứu trên các bệnh nhân tăng huyết áp của Trần Thị Mỹ Loan tại Việt Nam năm 2009, cũng cho thấy chỉ số BMI liên quan chủ yếu tới tăng cholesterol và Triglycerid [30]. Một số nghiên cứu trên thế giới chỉ ra rằng $\mathrm{BMI}$ liên quan khá chặt chẽ tới các chỉ số lipid máu, đặc biệt là cholesterol toàn phần và triglycerid [3133]. Như vậy, trên quần thể này, BMI chủ yếu liên quan tới huyết áp và các chỉ số lipid máu.

* Tương quan giữa chỉ số huyết áp và các yếu tố bệnh tim mạch

Trên các đối tượng nghiên cứu, chúng tôi nhận thấy có sự liên quan mật thiết giữa tăng huyết áp tâm thu và tăng huyết áp tâm trương. Mối tương quan này không phụ thuộc vào tuồi hay giới tính $(\mathrm{r}=0,8-0,9$ ở cả hai giới). Kết quả này tương đồng với các nghiên cứu trên cộng đồng [32]. Kết quả này càng thêm khẳng định tuổi là một yếu tố nguy cơ không thể thay đổi của các BTM. Khi tuổi tác lớn dần, hệ thống tim mạch cũng bước vào quá trình lão hóa. Ở mạch máu, các baroreceptor có nhiệm vụ kiểm soát huyết áp khi thay đổi tư thế và hoạt động cũng kém nhạy cảm hơn khi về già. Thành mao mạch dày lên, làm giảm lưu thông của máu và chất dinh dưỡng. Các động mạch chính của tim dày, cứng hơn và kém đàn hồi, làm tăng huyết áp và tăng gánh nặng cho tim, góp phần làm tim phì đại. Quá trình này cũng gặp ở các động mạch khác, vì vậy hầu hết người lớn tuổi đều mắc tăng huyết áp nhẹ. Trong nghiên cứu của chúng tôi, các chỉ số huyết áp ít có ảnh hưởng tới lipid máu. Điều này khá mâu thuẫn khi huyết áp tăng lại đi kèm với xu hướng tăng của một loại lipid tốt, vì vậy chúng tôi cho rằng cần nghiên cứu sâu hơn để làm sáng tỏ vấn đề này. Kết quả nghiên cứu của chúng tôi tương đồng với nghiên cứu của Bonaa và $\mathrm{cs}[32]$, tuy nhiên chưa có nhiều nghiên cứu tại Việt Nam phân tích về tương quan giữa các chỉ số này.

* Tương quan giữa chỉ số Lipid máu và các yếu tố bệnh tim mạch

Các chỉ số lipid máu có vai trò quan trọng trong việc sàng lọc và kiểm soát bệnh tim mạch. Sự thay đồi của từng yếu tố đều mang đến những tác động khác nhau. Tuy nhiên, bản thân các yếu tố này cũng có tác động qua lại, và khi kết hợp với nhau, chúng làm nguy cơ mắc BTM tăng lên đáng kể. Trong nghiên cứu của chúng tôi, có sự liên quan mật thiết giữa tăng cholesterol toàn phần với tăng LDL-c $(\mathrm{r}>0,6, \mathrm{p}$ $<0,05)$. Đặc biệt, có sự liên quan giữa tuổi với tình trạng tăng cholesterol toàn phần và tăng triglycerid trong nhóm nghiên cứu. Như vậy, nguy cơ BTM trên các đối tượng này rất đáng lo ngại.

Gần đây các nghiên cứu tại Việt Nam cũng như trên thế giới về mối liên quan giữa các chỉ số lipid này còn khá hạn chế. Dữ liệu từ năm 1991 trong nghiên cứu của Bonaa trên cộng đồng người châu Âu cho thấy mối tương quan không đáng kể giữa cholesterol toàn phần, triglycerid và $\mathrm{HDL}-\mathrm{c}$ [32]. Chúng tôi cho rằng cần có những nghiên cứu tiếp theo để tìm hiểu rõ hơn các mối tương quan này.

\section{Kết luận}

Tỷ lệ mắc các yếu tố nguy cơ thừa cân béo phì, tăng huyết áp, rối loạn mỡ máu trên đối tượng cán bộ một trường đại học ở Hà Nội năm 2016 lần lượt là $43,8 \% ; 12,3 \% ; 29 \%$. Nam giới có tỷ lệ mắc cao hơn nữ giới. Có sự liên quan 
giữa giới tính với tình trạng mắc hay không mắc thừa cân - béo phì, tăng huyết áp, rối loạn lipid máu $(\mathrm{p}<0,001)$. Nhóm tuổi liên quan chủ yếu tới tình trạng mắc tăng huyết áp $(\mathrm{p}<0,001)$.

\section{Lời cảm ơn}

Chúng tôi trân trọng cảm ơn sự tài trợ của Đại học Quốc gia Hà Nội cho đề tài mã số CS.17.04 để thực hiện nghiên cứu này.

\section{Tài liệu tham khảo}

[1] WHO. Cardiovascular diseases (CVDs) Fact sheet 2017 [Available from: http://www.who.int/mediacentre/factsheets/fs317/en/.

[2] Global Health Estimates 2015: Estimated deaths by age, sex and cause [Internet]. WHO. 2015.

[3] Federation WH. Risk factors 2017 [23/7/2017]. Available from: https://www.world-heartfederation.org/resources/risk-factors/.

[4] Bộ Y Tế. Chiến lược Quốc gia phòng chống bệnh không lây nhiễm giai đoạn 2015-2025. Hà Nội: Bộ Y tế; 2015.

[5] Việt NL. Kết quả mới nhất điều tra tăng huyết áp toàn quốc năm 2015 - 2016. 2016.

[6] Hạnh NTL. Tình trạng rối loạn dinh dưỡng Lipid và một số yếu tố liên quan ở người 25-74 tuổi nội thành Hà nội năm 2008. 2008.

[7] Thắng TX. Nghiên cứu các yếu tố nguy cơ bệnh tim mạch ở người $>25$ tuổi tại 2 quận huyện Hà Nội. Viện Tim mạch trung ương: Đại học Y Hà Nội; 2013.

[8] Lâm NT. Thống nhất phương pháp kỹ thuật sử dụng trong đánh giá thừa cân - béo phì của các nhóm tuổi khác nhau. Tạp chí DD\&TP. 2003;1.

[9] Bethesda. National High Blood Pressure Education Program. The Seventh Report of the Joint National Committee on Prevention, Detection, Evaluation, and Treatment of High Blood Pressure. 2004.

[10] National Heart Lung and Blood Institute. National Cholesterol Education Program: ATP III Guidelines At-A-Glance Quick Desk Reference 2002.

[11] Medicine Moh-GDoP. STEPS Vietnam 2015. 2016.

[12] Tan Van Bui, Christopher Leigh Blizzard, Khue Ngoc Luong, Ngoc Le Van Truong, Bao Quoc Tran, Petr Otahal, et al. National survey of risk factors fornon-communicable disease in Vietnam: prevalence estimates and an assessment of their validity. BMC Public Health. 2016;16(498).

[13] Quang Ngoc Nguyen, Son Thai Pham, Loi Doan Do, Viet Lan Nguyen, Stig Wall, Lars Weinehall, et al. Cardiovascular Disease Risk Factor Patterns and Their Implications for Intervention Strategies in Vietnam. International Journal of Hypertension. 2012;2012.

[14] Oanh TH Trinh, Nguyen D Nguyen, Philayrath Phongsavan, Michael J Dibley, Bauman AE. Prevalence and risk factors with overweight and obesity among Vietnamese adults: Caucasian and Asian cut-offs. Asia Pac J Clin Nutr 2009; 18(2):226-33.

[15] Helen L Walls, Anna Peeters, Pham Thai Son, Quang NN. Prevalence of underweight, overweight and obesity in urban Hanoi, Vietnam. Asia Pac J Clin Nutr. 2009;18(2):234-9.

[16] National Heart LaBI. Overweight and Obesity [Available from: https://www.nhlbi.nih.gov/healthtopics/overweight-and-obesity.

[17] Kiet A Ly, Thanh GN Ton, Quang V Ngo, Tung T Vo, Fitzpatrick AL. Double burden: a crosssectional survey assessing factors associated with underweight and overweight status in Danang, Vietnam. BMC Public Health. 2013;13(35).

[18] N. Jitnarin, V. Kosulwat, N. Rojroongwasinkul, A. Boonpraderm, Haddock CK. Prevalence of overweight and obesity in Thai population: Results of the National Thai Food Consumption Survey. Eat Weight Disord. 2011;16(4):242-9.

[19] Hee-Taik Kang, Jae-Yong Shim, Hye-Ree Lee, Park B-J. Trends in Prevalence of Overweight and Obesity in Korean Adults, 1998-2009: The Korean National Health and Nutrition Examination Survey. Journal of Epiemiology. 2014;24(2):109-16.

[20] WHO. Global Atlas on cardiovascular disease prevention and control. 2011.

[21] Duc Anh Ha, Robert J. Goldberg, Jeroan J. Allison, Thang Hong Chu, Nguyen HL. Prevalence, Awareness , Treatment, and Control of HighBlood Pressur e: A Population -Based Survey in Thai Nguyen, Vietnam. PloS ONE. 2013;8(6).

[22] Son PT. Hypertension in Vietnam, from comunity - based studies to a national targeted programme Umeå, Sweden: Umeå University, Hanoi Medical University; 2012.

[23] H Van Minh, P Byass, NTK Chuc, Wall S. Gender differences in prevalence and socioeconomic determinants of hypertension: 
findings from the WHO STEPs survey in a rural community of Vietnam. Journal of Human Hypertension. 2006;20:109-15.

[24] Kaplan NM. Cardiovascular risks of hypertension: UpToDate; 2016 [Available from: http://www.uptodate.com/contents/cardiovascularrisks-of-hypertension.

[25] Association AH. Understand Blood Pressure readings 2016 [updated 15/09/2017. Available from: http://www.heart.org/HEARTORG/Conditions/High BloodPressure/KnowYourNumbers/UnderstandingBlood-Pressure-

Readings_UCM_301764_Article.jsp\#.WdCnNNoX $7 \mathrm{X} 4$.

[26] Bùi Thị Nhung, Bình TQ. Rối loạn lipid máu ở người không béo bụng và có chỉ số khối cơ thể bình thường. Tạp chí $\mathrm{Y}$ học dự phòng. 2016;10(183):190.

[27] Wichai Aekplakorn, Surasak Taneepanichskul, Pattapong Kessomboon, Virasakdi Chongsuvivatwong, Panwadee Putwatana, Piyamitr Sritara, et al. Prevalence of Dyslipidemia and Management in the Thai Population, National Health Examination Survey IV, 2009. Journal of Lipids. 2014;2014:1-13.

[28] Huỳnh Ngọc Linh, Nguyễn Thành Trung, Khóa TQ. Đặc điểm rối loạn lipid máu và các yếu tố liên quan ở người từ 35 tuổi trở lên tại tỉnh cà Mau năm 2015. Tạp chí Y học dự phòng.2016;4(177): 39.

[29] Lê Thanh Chiến và các cộng sự. (2011), "Khảo sát mối tương quan giữa tăng huyết áp với BMI, vòng eo, tỉ số eo mông ở người dân phường Hòa Thạnh, quận Tân Phú ", Tạp chí Y học Thành phố Hồ Chí Minh. 15(4).

[30] Trần Thị Mỹ Loan và Trương Quang Bình (2009), "Tương quan giữa chỉ số khối cơ thể và rối loạn lipid máu ở bệnh nhân tăng huyết áp", Tạp chí Y học Thành phố Hồ Chí Minh. 13(1).

[31] Berit Lilienthal Heitmann (1992), "The effects of gender and age on association between blood lipid levels and obesity in Danish men and women aged 35-65 years", J Clin Epidemiol (45), tr. 693 - 702

[32] Kaare H. Bonaa và Dag S. Thelle (1991), "Association Between Blood Pressure and Serum Lipids in a Population", Circulation(83), tr. 1305-1314.

[33] Ichiro Wakabayashi (2004), "Relationships of body mass index with blood pressure and serum cholesterol concentrations at different ages", Aging Clinical and Experimental Research(14), tr. 461-466.

\title{
Risk Factors of Cardiovascular Disease among a Hanoi-based University's Staff
}

\author{
Vu Van Nga, Do Thi Quynh, Vu Thi Mai Anh, Vu Thi Thom \\ ${ }^{1}$ VNU School of Medicine and Pharmacy, 144 Xuan Thuy, Cau Giay, Hanoi, Vietnam
}

\begin{abstract}
In recent years, Vietnam has witnessed an increase in cardiovascular disease morbidity and mortality. This has given impetus to the current cross-sectional study to collect data on risk factors of cardiovascular disease through the 2016 annual physical exam result of 269 staff members aged from 20 to 64 from a Hanoi-based university. The prevalence of overweight - obesity, hypertension and dyslipidemia was $43.8 \%, 12.3 \%$ and $29.0 \%$, respectively. Men were more at risk than women. Compared with wider community, the prevalence of hypertension and dyslipidemia among the staff was considerably lower. There was an association between gender and these risk factors, while age generally affected hypertension $(\mathrm{p}<0.001)$.
\end{abstract}

Keywords: Cardiovascular disease risk factors, overweight and obesity, hypertension, dyslipidemia. 